\title{
$A R$ and VR technologies as tools for the formation of tourist attractiveness in the discourse of the development of the territorial brand "Made on the Don"
}

\author{
Irina Trubchik ${ }^{1, *}$, Nikita Kudinov $^{2}$, Olga Gnedina ${ }^{1}$, Oxana Popova $^{1}$, Andrey Shpigun ${ }^{1}$ \\ ${ }^{1}$ Don State Technical University, 1, Gagarin ave., 344003, Rostov-on-Don, Russia \\ ${ }^{2}$ AR project «ZRENIE 2.0», 1, Gagarin ave., 344000, Rostov-on-Don, Russia
}

\begin{abstract}
The current work covers the technological and marketing advantages brought by the application of augmented reality to the tourism cluster for the development of the territorial brand "Made on the Don". Theoretical part is built on the original theoretical framework formalizing media effect of the AR technology. The article explores key concepts from the works of David Alteide and Robert Snow (1979; 1988), Marshall McLuhan (1964; 1967), Bolter and Grusin (1999), and Lefebvre (1984).
\end{abstract}

\section{Introduction}

Now the Rostov Region is a dynamically developing region with diverse reserves of resources. Regional industry, trade, agriculture, service sector, infrastructure, science, education and culture are growing accordingly to its extensive functioning. The consistent economic complex distinguishes Rostov Region from other territorial entities of Russia. The relevance of forming a positive image of the region is undeniable, being largely determined by the choice of the most promising development options for it. Such options are formulated through the expanding cross-regional and international cooperation in order to promote a regional brand.

The first step to create a brand for the Rostov Region was done by establishment of a voluntary certification system, "Made in the Don," which sets significantly higher quality standards in relation to current legislation, taking into account the requirements of international standards, thereby stimulating entrepreneurs in various fields of activity to improve quality and competitiveness amongst business services. According to the interview with analyst I. Telarova [1], 46 types of Don products (from 22 enterprises) had been noted as highly promising for the expansion of regional brand for the first two years since the foundation of system "Made in the Don" (October 1, 2015).

The major development directions of the regional brand as well as its marketing and informational components are illuminated in the paper of N.P. Ketova et al. [2]. To implement projects boosting Don Territory as a tourist destintion, it is necessary to create unique tourist centers and routes, which have no analogues in the Russian Federation and in

* Corresponding author: trubchik@mail.ru 
the world, supporting the tourist folklore and historical centers that already existed today in the region: Starocherkassk, Taganrog, Veshenskaya and village of Tanais.

Importantly to note that promotion of any brand is impossible without the use of information technology in various aspects. A special role today is given to the use of augmented reality technologies, known to the majority of mobile users (under 40 years old), as well as computer/mobile games and immersive rooms in various amusement parks might be promising feature.

Contemporary research papers in the field of AI, network technologies and development of hardware component based on new materials and structures are rich enough to apply its outcome into practice, solving everyday tasks in a shorter time.

The media potential of augmented reality technology has not been studied and requires formalization in the context of the theory of media communications. Modern mobile technology, augmented reality (from English: augmented reality - AR), allows to display multimedia content on the top of graphic images or objects in real time using the software and hardware capabilities of personal mobile devices. For theorizing AR, fundamental concepts of media logic, mediation and remediation, social practices and social space will be considered. The next step of the paper is to overview a theoretical framework "Formalization of the AR media effect" authored by Nikita Kudinov. Novelty of that model is determined by dialectical approach for analyzing AR as an information medium, what allows to explore the deep structural interdependencies of technology and society.

\section{The media potential of augmented reality technology}

To realize the media potential of $\mathrm{AR}$, it is important to understand its logic as a communicative medium. Firstly, there is need to turn to the works of American sociologists, David Alteide and Robert Snow [3], who introduced the concept of media logic, the "cornerstone" of the modern theory of media communications, into the academic field. Taking into account that traditional sociological approaches to the media are trying to limit the field of influence of the media on the general prerequisites for socio-cultural life, Alteide and Snow want to show how the logic of the media forms a fund of knowledge and practices generated and disseminated in society. Based on the classical works of sociology by Georg Simmel, Alteide and Snow argue "the primacy of form over content", where the media logic is comparable to the formatting logic, determining the positions and processes of constructing a message in accordance with the functional characteristics of the medium [4].

The authors define "media logic" (from English: media logic) as an aggregate form of communication that mediates transmission processes information. The fundamental principle of media logic is that the logic of actions of subjects reflects information technology and media formats that govern the rules of communication. The derived principle postulates that the accepted rules of communication are institutionalized, taken for granted and serve as an interpreting scheme for the routine of social interaction. Thus, media logic plays a key role in creating, maintaining and changing social practices.

A case-study academic example of this influence is the case of Kennedy and Nixon, candidates for the 35th US President. At the first television presidential debate in 1960, Kennedy emerged victorious because he "used the opportunities offered by television," such as antiperspirant makeup and a dark suit that set him apart from the studio's light background [5]. As a result of such preparations, his image was differentiated against Nixon, who was dressed in a pale suit (therefore merged with the walls) and sweated under studio spotlights. Kennedy won the sympathy of the public "no matter what he actually said," because his television image became the denominator of the political credibility of candidates, instead of the professional qualities proposed by Nixon. After winning the 35th 
US Presidential election, Kennedy said that television was crucial in his victory. [6] Interestingly, the listeners were more sympathetic to Nixon, but there were more viewers. This example illustrates how the penetration of the media, especially television, into the everyday life of $60 \mathrm{~s}$ Americans led to the emergence of new requirements for politicians: the appearance, manner of behavior and style of the candidate became the most important indicators for achieving electoral sympathy.

The process of the influence of media logic on social life is called "Mediation" (from the English language: mediatization) or "mediation" (from the English language: "Mediation"), which in Russian will be interpreted as "mediation". Despite the different terminology used in the academic environment, the key function of such a process is to structure all social interactions [7].

The innovative view proposed by the Canadian academician of media communications, Marshall McLuhan (1964; 1967), laid the foundation for theorizing the processes of media influence on the formation of public perception and practice. In 1964, McLuhan identified a general characteristic for all information communication tools, noting that the content of one medium is also another medium. Discussing by the example of transmitting a message by telegraph, McLuhan illustrates the relationship of various mediums of information: telegraph content - print, print content - written word, letter content - speech. However, being a telegraph message, written speech is mediated by an electrical signal, which eliminates the temporal and spatial factors of human communication. Thus, each new medium mediates the previous one, affirming a new communicative context for the exchange of information. At the end of XX century. McLuhan's thesis "the medium is the message" (from the English language: "the medium is the message") becomes the fundamental position of the theory of media communications, and is relevant today [8,9].

Starting from McLuhan's position, Bolter and Grusin (1999) introduce the term "Remediation" (from the English language: "remediation"), which is identical to the process of transformation and absorption of old media communications by new ones. Having carried out a detailed study of a wide range of media of humanity, Bolter and Grusin believe that "our culture seeks to both increase the communication media and erase all traces of their presence" [10]. The process of remediation reflects such a socio-cultural principle in the form of dialectical logic. The dialectics of remediation is manifested as a synthesis of epistemological dichotomy immediacy / hyper-mediation. If immediacy involves a single visual space, leveling out the presence of mediums, then hyper-mediation offers a heterogeneous space, segmented into many media representations.

The authors illustrate such dialectic logic using the example of the traditional media being remediated by digital ones [11]. New media formats rely on the old, as the latter are normalized practices of the socio-cultural context. Digital media seeks to correct the shortcomings of previous forms of communication through more direct (immersive) formats of perception of content. For this, it is necessary to more strongly mediate sensory perception, which requires the animation of mediums. As a result, newly introduced mediums require normalization in the socio-cultural context through the adaptation of social practices to the proposed innovations. As these practices normalize, old mediums also undergo a dialectical transformation, integrating new formats. For example, the structure of modern billboards is comparable to the segmented space of web pages. Thus, the process of remediation illustrates the transformation of media logic as an aggregate form of communication.

Among modern media formats, Bolter and Grusin emphasize that AR transforms the window style of the desktop, presenting elements of computer graphics as real objects that can affect the physical space. Being an intermediary between the viewer and the physical world, AR postulates mediated reality [12]. 
To understand impact of AR on the socio-cultural context, let's turn to Henri Lefebvre, a French Marxist and sociologist of the 20th century, for help. Working on his legendary work, The Production of Space (1984), Lefebvre was grateful to McLuhan for his innovative theoretical position, which should have helped the first in writing the book. Indeed, the medium according to McLuhan means not so much the information means of communication as the medium / space mediated by communications. Such an unconventional look allows McLuhan to assert that space (as a context for the exchange of information) is a sensual extension of a person, shaping his perception. In turn, Lefebvre conceptualizes social space as a product of the activity of society, and the substrate that forms social practices. Such a space is concrete and material, mediated by social relations, which are established and maintained as a result of social practices used by individuals [13].

Pursuing the traditions of humanistic Marxism, Lefebvre describes the nature of social space in various categories of dialectics. As part of the current work, the discourse of the class struggle should be omitted and a simplified interpretation of the Lefebvre dialectic should be avoided, adhering to the subject of research. According to Lefebvre, the dynamics of social space is expressed through a dialectical synthesis of a homogeneous and differentiated space - products of various social practices. A homogeneous social space, being a product of directly established social practices, is transformed into a qualitatively new one, as soon as it becomes quite indirectly differentiated space, a product of new practices. The further process of normalization and dissemination of practices is a consequence of the transformation of social space $[14,15]$.

The concept of the production of social space proposed by Lefebvre is identical to the principle of remediation by Bolter and Grusin, formalizing the dialectical postulation of the media effect of AR technology. Indeed, mediated reality in the form of a real-virtual synthesis implies the reform of not only ideas about physical objects accompanied by AR content, but also the social space in which these objects are located.

Given the above logic of the article, an understanding of the media effect of AR is based on a two-stage cyclic dialectical process of remediation, transforming the landscape of social practices:

1. Mediation. The introduction of AR in the social space leads to the emergence of new and transformation of old social practices, as it assumes their differentiation and formatting in accordance with the medium. Such AR-mediated practices postulate new connotations of space that contribute to their further cultivation.

2. Normalization. If practices are successfully cultivated among the audience, then there is widespread differentiation of social space. Such a massive phenomenon initiates the subsequent institutionalization of new regulatory models for interpreting social space, which signals fundamental changes in the current media logic.

The described structural transformation under the influence of AR is presented in the form of an applied theoretical framework in Figure 1: 


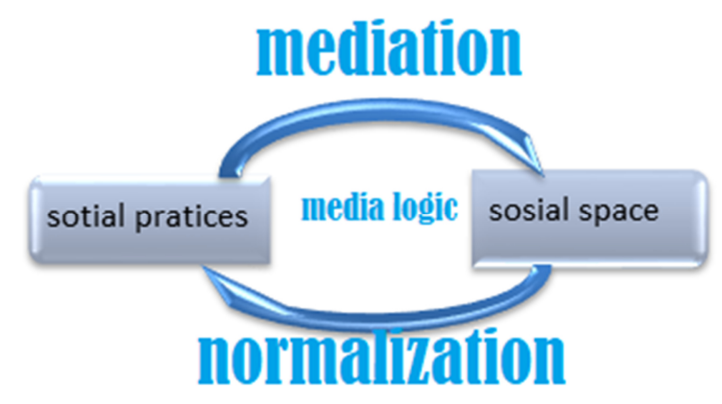

Fig. 1. Formalization of the AR media effect, applied theoretical framework authored by Nikita Kudinov.

The resulting model allows us to analyze the effect of the implementation of AR and offers to predict the transformation of social practices in the form of structural reflection of social dynamics relative to the mediated space.

\section{Some features of the architecture and logic of application development using virtual and augmented reality technologies}

The idea of introducing reality into everyday life and its use, in particular in the tourism sector, cannot be realized without proper equipment with the necessary technologies and software such as SketchUp, Revit, 3D-Max and SolidWorks. Thus, it is possible to load objects of interest to promoters directly from established libraries without the help of company employees. This feature opens up completely different possibilities. No printed sheets of paper are needed anymore. The user simply points the gadget to the desired location, selects a model from the catalog to experience it in 3D format. It is also possible to substitute this image in a real interior, complementing with reality.

Among real-time object solutions, the Urbasee Future project offers an interesting technology: a model of object is uploaded to the server, being attached to a specific geolocation (for example, to the place where there will be a detailed museum exposition or a point of promotion of branded products). The application is synchronized with the server, and, being at that location, instead of empty space displays a 3D image of the object in a $1: 1$ scale. It is likely that in such operating time, user can use it to create its own information stands with authoring applications that allow to see how the displayed object looks in reality.

Figure 2 shows the architecture of the interaction between the end user and outside world through various components of the AR information system. 


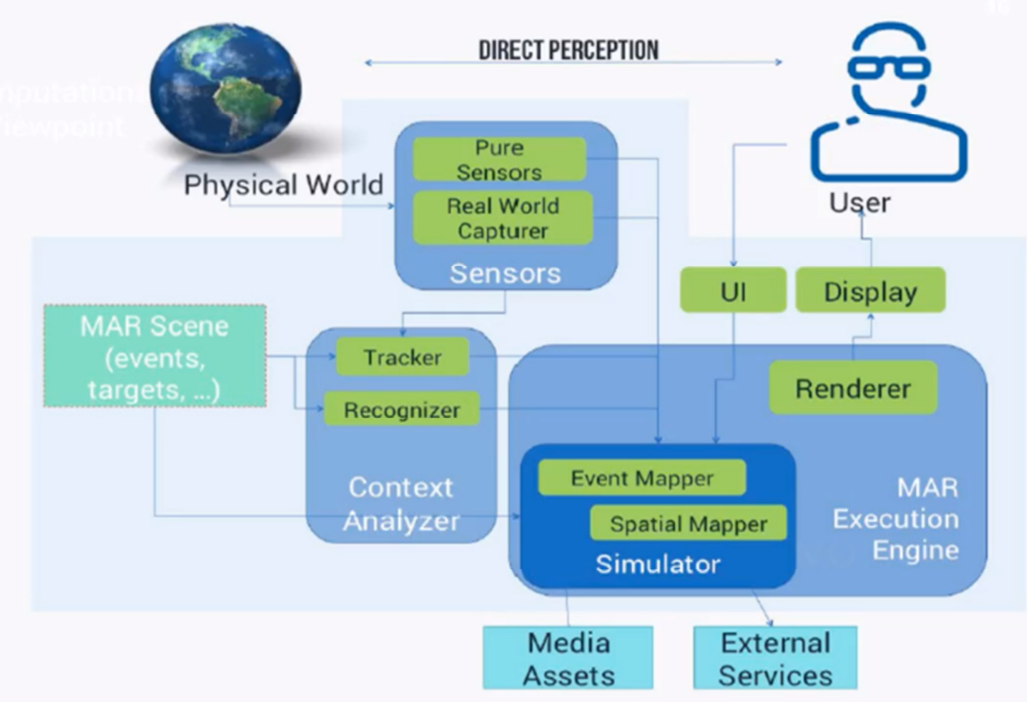

Fig. 2. Applied technology framework: architecture of the AR/VR interaction between Physical World and User.

In order to realize the tasks of updating "Made on the Don" brand, it would be more convenient to assemble all these components into a single whole, creating a kind of viewer in the form of an application that is simple enough and at the same time capacious in order to make AR technology more accessible for end user. Namely, it is proposed to advance an existing AR regional application "ZRENIE 2.0" (iOS and Android) to incorporate all the architectural and technological features of the interaction described in Figure 2. The final interaction scheme in this case takes the form shown in Figure 3.

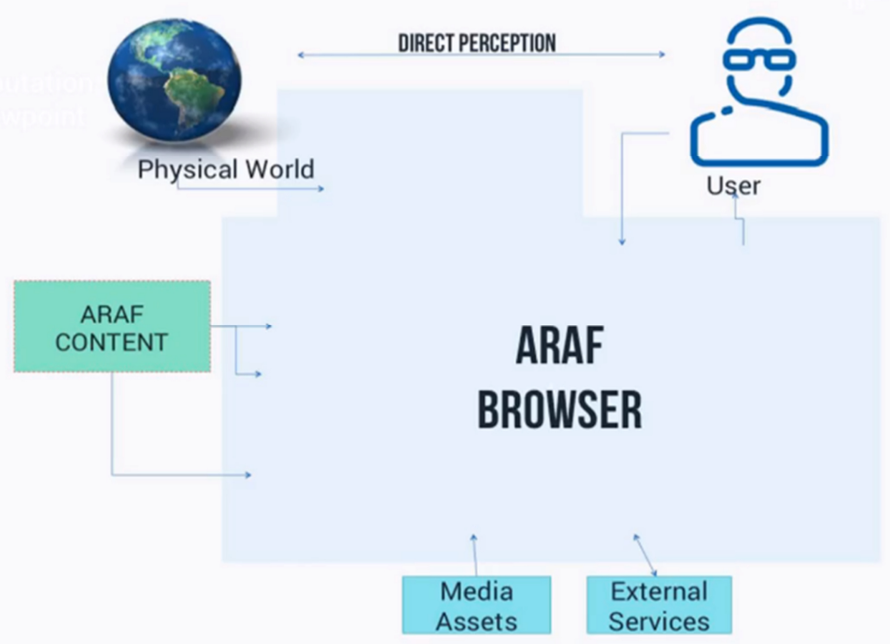

Fig. 3. Model of ARAF browser.

Today, the sphere of augmented reality is considered as one of the fastest growing. Corresponding technologies have entered an active stage of development over the past five years, and according to experts, they will need another 5-10 years to produce something 
like a revolution. And even though Google Glass couldn't capture the market the first time, it's clear that new developments bring benefits to everyone. Finally, AR will unite all participants of the construction process into a single visual information field, delegating a pile of drawings and constant binding to the personal mobile devices.

\section{Practical implementation}

The current article is looking for further application of the theoretical arguments towards real practice. Promotion of the territorial brand "Made on Don" is currently possible within AR technology relying on the existing regional AR project "ZRENIE 2.0".

Numerous application of AR for different regional activities had been done during the last 3 years by "ZRENIE 2.0": (1) for the tourism: supporting information materials for the Department of Tourism Development of Rostov-on-Don and exposition materials for the travel agency Reyna Tour; (2) digitalization of educational materials - an international project, the creation of an interactive textbook for studying Russian by Chinese students "WE"; (3) case at the intersection of education and tourism: AR accompaniment of the pages of the book "Quiet Don"; (4) social sphere: proposal of a PR campaign for Roskomnadzor to inform schoolchildren about measures to protect personal data; (5) pilot implementation of AR in regular print - fashion magazine "Dog"; (6) at the last meeting on the development of the consumer market, the technology for promoting Don wines at the international level was presented to the governor of the Rostov region; (7) at the last Russian-Chinese Forum, a video was shown about the city of Rostov on the cover of the Russian passport.

Nowadays team of the digital project "ZRENIE 2.0" is working on placing entertaining, social and educational content in the urban information space of augmented reality, providing user access through the mobile application "ZRENIE 2.0" for mobile platforms IOS and Android. The major aim of the project is to digitalize infrastructure of main urban clusters is Russia by 2023.

\section{Acknowledgements}

A theoretical framework «Formalization of the AR media effect» is established by Nikita Kudinov.

\section{References}

1. I. Telarova, Don priorities. Email Journal Interview (2015) http://dpregion.ru/articles/interview/irina-telarova-predlagaya- potrebitelyu-kachestvennuyuproduktsiyu-so-znakom-sdelano-na-donu/

2. N.P. Ketova, E.D. Tasina, V.N. Ovchinnikov, Formation of a positive brand in the region: taking into account the features of peripheral territories, marketing mechanism for implementation (Assistance-XXI Century, Rostov n/D, 2015) https://portu.ru/elektronm2/1696-osnovnye-cherty-territorialnogo-compleksa-rostovskoj-oblasti

3. D.

Altheide, Media

Logic https://www.researchgate.net/publication/313386386_Media_Logic\#pf5

4. D. Altheide, Media Logic, Social Control, and Fear Communication Theory 23(3) (2013) DOI: 10.1111/comt.12017

5. P.P. Verbeek, Technoscience and Postphenomenology (Lexington Books London, 2016) https://ris.utwente.nl/ws/portalfiles/portal/21754033/theory_of_mediation.pdf 
6. P.-P. Verbeek, Technoscience and Postphenomenology (Lexington, Manhattan, 2016)

7. A. Cristiano, Millennials and Media Ecology (2019) DOI: 10.4324/9780429259234-3

8. A. Galey, Reading McLuhan Reading Ulysses (2019) DOI: 10.22230/cjc.2019v44n4a3717

9. J.S.J. Kirchoff, Beyond remediation: Comic book captions and silent film intertitles as the same genre (2012) DOI: 10.1386/stic.3.1.25_1

10. R. Louis Martinez-Davila, L. Ramey, Routledge Research Companion to Digital Medieval Literature (Routledge, 2018)

11. E. Rabenu, S. Shkoler, International Student Mobility and Access to Higher Education (2020) DOI: 10.1007/978-3-030-44139-5_5

12. V. Kumar Sivarama, N. Sharma Show, M.M. Hanafiah, Intelligent Nanomaterials for Drug Delivery Applications (Elsevier, 2020) DOI: 10.1016/B978-0-12-8178300.00009-6

13. J. Street, Mass Media, Politics \& Democracy, 2nd Edition (Macmillan, Basingstoke and New York, 2011)

14. K. Webley, How the Nixon-Kennedy Debate Changed the World (2010) http://content.time.com/time/nation/article/0.8599,2021078,00.html 